\title{
Seizure-Induced Changes in Place Cell Physiology: Relationship to Spatial Memory
}

\author{
Xianzeng Liu, ${ }^{1,2,3}$ Robert U. Muller, ${ }^{4,5}$ Li-Tung Huang, ${ }^{2}$ John L. Kubie, ${ }^{4}$ Alexander Rotenberg, ${ }^{2,4}$ Bruno Rivard, ${ }^{4}$ \\ Maria Roberta Cilio, ${ }^{2}$ and Gregory L. Holmes ${ }^{1,2}$ \\ ${ }^{1}$ Neuroscience Center at Dartmouth, Division of Neurology, Dartmouth Medical School, Lebanon, New Hampshire 03756, ${ }^{2}$ Children's Hospital Boston, \\ Harvard Medical School, Boston, Massachusetts $02115,{ }^{3}$ Department of Neurology, People's Hospital, Peking University Health Science Center, Beijing, \\ China 100044, ${ }^{4}$ Department of Physiology and Pharmacology, State University of New York at Brooklyn, Brooklyn, New York 11203, and ${ }^{5}$ Medical Research \\ Council Centre for Synaptic Plasticity, Department of Anatomy, University of Bristol, Bristol, United Kingdom, B58 1TD
}

Status epilepticus (SE) is a frequent neurological emergency associated with a significant risk of morbidity in survivors. Impairment of hippocampal-specific memory is a common and serious deficit occurring in many of the survivors. However, the pathophysiological basis of cognitive deficits after SE is not clear. To directly address the cellular concomitants of spatial memory impairment, we recorded the activity of place cells from CA1 in freely moving rats subjected to SE during early development and compared this activity to that in control rats. Place cells discharge rapidly only when the rat's head is in a cell-specific part of the environment called the "firing field." This firing field remains stable over time. Normal place cell function seems to be essential for stable spatial memory for the environment. We, therefore, compared place cell firing patterns with visual-spatial memory in the water maze in SE and control rats. Compared with controls, place cells from the SE rats were less precise and less stable. Concordantly, the water maze performance was also impaired. There was a close relationship between precision and stability of place cells and water maze performance. In contrast, a single, acute, chemically induced seizure produced cessation of place cell activity and spatial memory impairment in water maze performance that reversed within $24 \mathrm{hr}$. These results strongly bolster the idea that there is a relationship between abnormal place cells and spatial memory. Our findings also suggest that the defects in place cell and spatial memory after SE and acute chemically induced seizures result from different processes.

Key words: water maze; epilepsy; status epilepticus; memory; place cell; seizures

\section{Introduction}

Status epilepticus (SE), which is defined as $30 \mathrm{~min}$ or more of continuous epileptic seizure activity, is a common neurological emergency in children associated with high morbidity and mortality (Aicardi and Chevrie, 1970, 1983; DeLorenzo et al., 1992; Working Group on Status Epilepticus, 1993; van Esch et al., 1996; Sahin et al., 2001). Although SE with or without recurrent seizures is associated with a wide variety of neuropsychological problems, memory deficits including impairment of episodic memory are especially prominent (Jambaque et al., 1993; Krumholz et al., 1995; van Esch et al., 1996). It is, therefore, of paramount interest to identify the processes by which SE leads to permanently abnormal brain function, to prevent the operation of such processes, or to reduce their effects afterward.

A great deal of evidence suggests that normal declarative

Received July 15, 2003; revised 0ct. 9, 2003; accepted 0ct. 9, 2003

This work was supported by National Institute of Neurological Disorders and Stroke Grants NS27984 and NS44295 (G.L.H.), an American Epilepsy Foundation fellowship (X.L.), National Institutes of Health Grants NS20686 and NS37150 (R.U.M.), and a grant from the Medical Research Council (United Kingdom) (R.U.M.). We thank Emerson S. Hawley for hardware technical support.

Correspondence should be addressed to Dr. Gregory L. Holmes, Center for Neuroscience at Dartmouth, Dartmouth-Hitchcock Medical Center, One Medical Center Drive, Lebanon, NH 03756. E-mail: Gregory.L.Holmes@Dartmouth.edu.

Copyright $(\odot 2003$ Society for Neuroscience $\quad 0270-6474 / 03 / 2311505-11 \$ 15.00 / 0$ memory, the ability to learn and recall specific information about people, places, and events, depends on a properly functioning hippocampus (Squire, 1992). In light of the memory deficits seen after SE in humans, it is not surprising that SE is preferentially associated with histologically detectable damage of the hippocampus and related areas ("mesial temporal sclerosis"). This form of damage is characterized by cell loss in CA1, CA3, the hilus and dentate gyrus, and synaptic reorganization as evidence by sprouting of mossy fibers (Liu et al., 1995). Although the precise role of cell loss and synaptic reorganization in the sequelae of SE is unclear, there is evidence that other processes, including recurrent seizures, may play important roles in memory deficiencies (Hermann et al., 2002; Stefan and Pauli, 2002).

Thus, little is certain about the pathophysiological mechanisms responsible for the adverse events after SE, including the memory loss. It is clear, however, that the participation of cell level processes in these events is extremely difficult to study in humans. It is, therefore, hard to avoid the conclusion that progress toward a complete understanding of SE will require the use of animal models.

To directly address the cellular concomitants of spatial memory impairments, we recorded the activity of single hippocampal neurons in freely moving rats subjected to SE during early development and compared this activity to that in control rats. Al- 
though such recordings in a primary locus of SE-based damage are of intrinsic interest, they have additional impact because many individual pyramidal cells of CA1 and CA3 in normal rats act as "place cells." Each place cell discharges rapidly only when the rat's head is in a cell-specific part of the environment called the "firing field." Moreover, firing fields are stable over long times (weeks or months) in a constant environment, implying that the across-cell representation is remembered and not created de novo each time the rat enters the environment (Muller and Kubie, 1987; Muller et al., 1987; Thompson and Best, 1989, 1990).

We now report that adult rats who experienced SE during early development showed deficient performance in two variants of a complex spatial task, the Morris swimming task, and, in parallel, have defective place cells, as expected from the spatial mapping theory. The place cells from the SE rats are defective in two ways: (1) their firing fields are less orderly than those of normal rats; and (2) their firing fields are less stable than those of normal rats. Each of these defects provides a reasonable explanation of why water maze performance is deficient in SE rats.

These results demonstrate that SE has consequences that are reflected at the cellular level in the hippocampus, the brain region implicated in declarative memory in humans and spatial memory in rodents. The results provide a substrate for following the time course over which place cell abnormalities develop in SE rats and how these abnormalities are related to the appearance, frequency, and severity of seizures. Preliminary results with acutely induced seizures in normal rats reveal a very different pattern of place cell pathology from that seen in SE rats, suggesting that the effects of acute seizures may be additive to the long-term effects of SE.

\section{Materials and Methods}

Overview. The goals of the study were to evaluate the effects of SE in adolescent rats on place cell firing patterns when the animals were adults. We elected to use weanling rats because we have previously established that $\mathrm{SE}$ in this age group is associated with substantial histological and behavioral deficits when the animals are studied as adults (Faverjon et al., 2002; Rutten et al., 2002; Cilio et al., 2003). In addition, children have a high risk for SE and SE-induced damage (van Esch et al., 1996; Shinnar et al., 1997); however, the mechanisms for the cognitive impairment after $\mathrm{SE}$ in children are unclear.

Once the animals were adults, place cell measurements were obtained. A subset of animals underwent EEG monitoring during place cell acquisition. To determine whether there was a relationship between place cell firing patterns and cognitive function, control and SE rats underwent testing in the water maze, a test of visual-spatial memory. Animals were tested in either a small or large swimming tank. Because rats may develop spontaneous seizures after SE, monitoring for seizures was done throughout the place cell recordings and water maze testing.

In a separate group of control rats after place cell recordings, rats were obtained. After training to asymptote performance in the water maze, animals were subjected to brief, flurothyl-induced generalized seizures, and place cells and water maze performance were recorded during the recovery period. The study was designed to allow us to evaluate both the chronic effects of SE and the acute effects of seizures on cognitive function and place cell firing.

Rats and lithium-pilocarpine-induced seizures. The experimental procedures were approved by the Animal Care Committee of Children's Hospital Boston and were performed in accordance with National Institutes of Health guidelines for the humane treatment of animals. Male Sprague Dawley rats were divided into a control group $(n=27)$ and a lithium-pilocarpine seizure group $(n=28)$. They were maintained on a $12 \mathrm{hr}$ light/dark cycle and had ad libitum access to food and water, except during place cell recording. For the seizure group, lithium chloride (3 $\mathrm{mEq} / \mathrm{kg}$ ) was given intraperitoneally $18 \mathrm{hr}$ before a subcutaneous injection of pilocarpine $(60 \mathrm{mg} / \mathrm{kg})$ on postnatal day (P) 20 to induce SE, as described previously (Faverjon et al., 2002; Rutten et al., 2002; Cilio et al.,
2003). For the control group, normal saline was given intraperitoneally $18 \mathrm{hr}$ before a subcutaneous saline injection on day P20. After injections, the rats were placed in group cages (three rats per cage) without the dam.

Behavioral training. Twelve control rats and $18 \mathrm{SE}$ rats were selected for place cell recordings using methods similar to those of Muller et al. (1987). Place cell recordings were performed between P80 and P110. The recording area was a gray cylinder $76 \mathrm{~cm}$ in diameter and $51 \mathrm{~cm}$ high placed on a piece of gray paper that was replaced between each session. A sheet of white cardboard occupied $90^{\circ}$ of inside arc of the cylinder and was the only polarizing stimulus. The card was centered at 3:00 as seen from overhead. The cylinder was centered in a circular curtain, the bottom of which was just above the floor and the top of which was just below the ceiling. The cylinder floor was illuminated by eight $25 \mathrm{~W}$ bulbs evenly spaced around the curtain.

The key requirement for place cell recordings was for the rat to visit all parts of the cylinder. To this end, hungry rats learned to chase $45 \mathrm{mg}$ food pellets dropped from an overhead feeder. On the first training day, the rat was put in the cylinder with $\sim 50$ pellets scattered on the floor. The rat remained in the cylinder for $30 \mathrm{~min}$, during which time it walked around and ate the food. On subsequent training days, pellets were dropped randomly in various locations throughout the cylinder at an average rate of $\sim 3 / \mathrm{min}$. Training was completed when the rat spent a minimum of 12 of the 16 min walking.

Electrode implantation. The movable array of $1625 \mu \mathrm{m}$ electrodes was modified from the method of Kubie (1984). Before surgery, rats were anesthetized with intraperitoneal pentobarbital ( $40 \mathrm{mg} / \mathrm{kg}$ ). Supplemental chloral hydrate $(300-600 \mathrm{mg} / \mathrm{kg})$ was given intraperitoneally as needed. Electrode implantation was done under sterile conditions. The rat was put in a stereotaxic frame, the skull was exposed, and anchor screws were put into the skull over the right olfactory bulb, left frontal cortex, and right cerebellar hemisphere. A $2 \mathrm{~mm}$ hole was made in the right parietal bone. The dura was removed to expose the brain surface. The initial placement of the electrode tips was $3.8 \mathrm{~mm}$ posterior to bregma, $2.5 \mathrm{~mm}$ lateral to midline, and $1.5 \mathrm{~mm}$ below dura, directly above the dorsal hippocampus (Paxinos and Watson, 1998). Sterile petroleum jelly was applied to the exposed brain surface and the electrode guide tube. Grip cement was applied over the jelly, around the tube, and onto the skull and anchor screws. Neosporin ointment was applied to the cut skin. Rats were given several days to recover from surgery before recordings were begun.

Electrophysiological recording. Electrical activity was first amplified $(1 \times)$ on the rat's head and then amplified $(10,000 \times)$ with a differential AC amplifier and bandpass filtered $(300-10,000 \mathrm{~Hz})$. Spikes were digitized $(33 \mathrm{kHz})$ and later discriminated with a DataWave system (DataWave, Boulder, CO). Discrimination was done from single wire probes using spike height, spike width, and the voltage. Spike height was the difference between maximum peak and depth of the waveform, and spike duration was the time interval between the initial and final deflection. Initial discrimination was made before a session, but waveforms were always saved to allow refinement of discrimination off-line.

To permit unbiased estimates of the fraction of cells with different properties, we established a fixed rule: if the peak-to-peak amplitude of any waveform was $<150 \mu \mathrm{V}$, it was rejected; if the amplitude was $\geq 150$ $\mu \mathrm{V}$, it was always recorded. After recording, discriminated waveforms were sorted into pyramidal cells and interneurons (Ranck, 1973; Fox and Ranck, 1975, 1981). To be classified as a pyramidal cell, the unit had to: (1) fire complex spike bursts (decrementing spike sequences with interspike interval $<5 \mathrm{msec}$ ) (Fig. 1); (2) have a negative initial phase $>300$ $\mu$ sec; and (3) show silent intervals of at least $1 \mathrm{sec}$ in duration. To be classified as an interneuron, the unit had to: (1) never fire complex bursts; (2) have a negative initial phase $<300 \mu \mathrm{sec}$; and (3) never show silent intervals $>0.2 \mathrm{sec}$.

Before recordings, each electrode was checked for waveforms of sufficient amplitude. If none were detected, the electrode array was advanced $20 \mu \mathrm{m}$ and the rat was returned to its home cage for $4-6 \mathrm{hr}$. This sequence was repeated until one or more pyramidal cells with $\geq 150 \mu \mathrm{V}$ were isolated. Each cell or group of cells was recorded for $64 \mathrm{~min}$ in two pairs of 16 min sessions. The first pair of sessions was separated by a 2-3 min interval. After the second session, the rat was returned to its home 
A
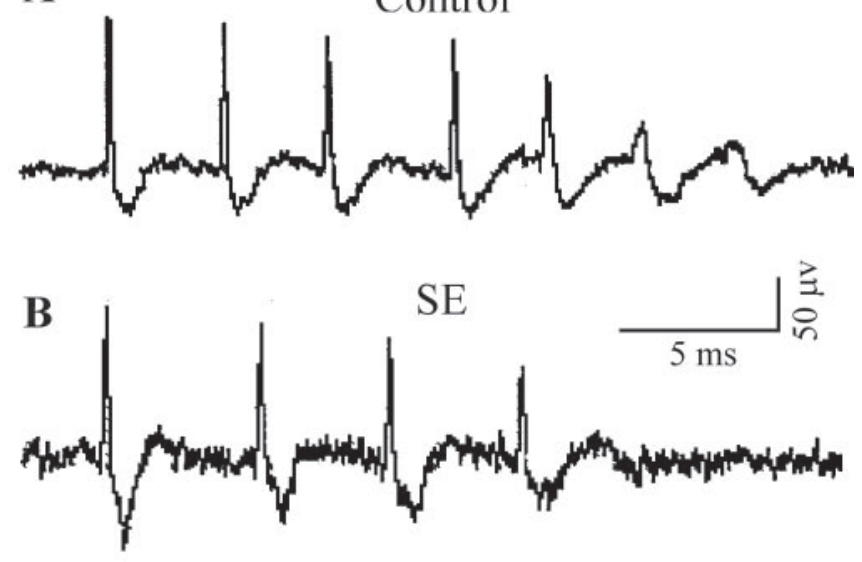

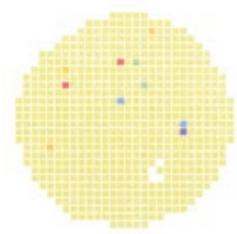

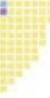

D

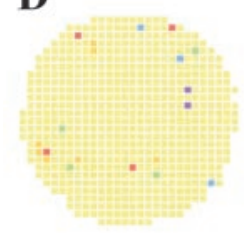

C Silent

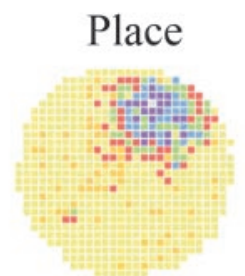

Control

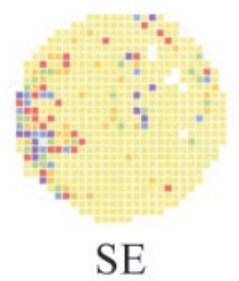

SE
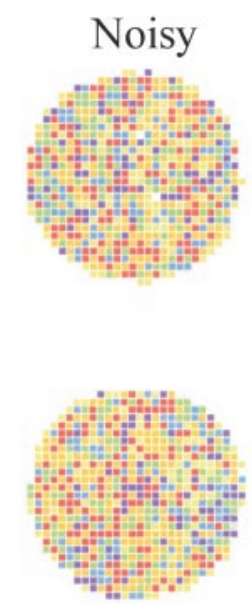

Figure 1. Basic pyramidal cell properties. $A, B$, Complex spikes recorded from a control rat $(A)$ and an SE rat $(B)$. Note the very short ( $<5 \mathrm{msec}$ ) time interval between spikes and the decrementing amplitude of later spikes. No differences in the configuration of these bursts were noted between normal and SE rats. C, D, Examples of silent, place, and noisy cells from a control $\operatorname{rat}(C)$ and an SE rat $(D)$. The firing field for the control place cell is the dark region at 1:00; for the place cell from the SE rat, the field is at 8:30.

cage for 4-6 hr. It was then put back in the cylinder for sessions 3 and 4 , which were also separated by a 2-3 min break. Thus, there were two short-interval session pairs (S1-S2 and S3-S4) and four long-interval session pairs (S1-S3, S1-S4, S2-S3, and S2-S4).

Tracking position. The position of a light-emitting diode (LED) on the head was tracked with an overhead television camera at $60 \mathrm{~Hz}$ in a $64 \times$ 64 array of square pixels $2.7 \mathrm{~cm}$ on a side. The total time the LED was detected in each pixel, and the number of spikes fired in each pixel was accumulated. A time-averaged firing rate distribution was calculated by dividing the number of spikes in each pixel by the dwell time in that pixel. Color-coded firing rate maps were used to visualize positional firing distributions. Pixel rates were coded in the sequence yellow, orange, red, green, blue, and purple. The firing rate was exactly zero for yellow pixels. Unvisited pixels in the cylinder and pixels outside the cylinder were coded white.

EEG and video monitoring. In another eight SE rats and four control rats, two additional electrodes on the same headset were used for recording the EEG. Two straight $75 \mu \mathrm{m}$ nichrome wires were glued together, with one cut $0.8-1.0 \mathrm{~mm}$ shorter than the other. The EEG electrodes were fixed at $3.5 \mathrm{~mm}$ anteroposterior and $2.5 \mathrm{~mm}$ lateral, with respect to the bregma, with the longer electrode aimed at the hippocampal fissure and the shorter electrode aimed dorsal to the CA1 stratum pyramidale. The 26 gauge cylinder through which the place cell electrodes were threaded served as the reference electrode. The ground electrode for the EEG recordings was a skull screw placed over the right cerebellum. This electrode arrangement allowed us to record fissure theta (Brazhnik et al., 2003). When the EEG was in the theta state, the two channels phase reversed relative to each other with the positive phase of the theta displayed upward. The EEG was collected through the same preamplifier used for the place cell recording, then amplified $1000 \times$ times by another differential AC amplifier, bandpass filtered at $0.1-300 \mathrm{~Hz}$, and digitized at $1 \mathrm{kHz}$. Rats were monitored continuously for behavioral and electrographic seizures during the place cell recordings.

These 12 rats also underwent video monitoring every other night for 1 month. Eight-hour recordings were from 6:00 P.M. to 2:00 A.M., and the tapes were reviewed the next day for behavioral seizures by experience behavioral technicians. All recorded seizures were also reviewed and verified by G.L.H. or X.L. On scheduled recording days, rats were also video taped for $6 \mathrm{hr}$ before being placed in the behavioral chamber for the two early sessions, during the sessions, for 3-4 hr between sessions, and during the two late sessions. Animals with seizures during this period of time were not studied. In addition, we recorded EEG during the place cell recordings in eight rats in the experimental group.

Data analysis. Place cells were recorded in 8 of 12 control rats and 12 of $18 \mathrm{SE}$ rats. In four control rats and six SE rats, cells recorded did not meet our criteria for inclusion as place cells, noisy cells, or silent cells. Our description of positional firing patterns is based on the idea that a place cell has a distinct, contiguous location in which it reliably discharges. To identify a firing field, the following rules were applied: (1) a pixel could be included in a field if its firing rate was $>0$; (2) to be part of a field, a pixel had to share an edge with a pixel already known to be in the field; and (3) the minimum field size was nine pixels. In the present analysis, if two or more fields were identified for a cell, only the largest field was considered. On this basis we measured: (1) field area: the number of pixels included in the field; (2) field rate: the firing rate averaged over all pixels in the field; (3) field center rate: for each pixel in the field, the average of its rate and the rate in its eight nearest neighbors is calculated. The peak rate is that in the pixel for which this average is greatest; and (4) coherence: this is a two-dimensional nearest-neighbor autocorrelation. It is calculated by listing the firing rate in each pixel and the average firing rate in its eight nearest neighbors. Coherence is the $Z$-transform of the correlation between these lists. It estimates the local smoothness of the positional firing pattern. An impression of the meaning of coherence can be gained from Figure 2 .

Based on positional firing rate distributions, CA1 complex-spike cells were categorized as place cells, silent cells, or noisy cells (Rotenberg et al., 1996, 2000) (Fig. 1). Place cells had one, or in a few cases, two clear firing fields. Silent cells fired only a few action potentials without sufficient density to have a firing field. Noisy cells fired at an average rate $>1.0$ spike/sec but had none of the distinct silent areas that characterize place cells recorded in these circumstances.

Using these criteria, an initial categorization was first made by visual inspection of firing rate maps by two investigators (G.L.H. and X.L.) who agreed in all cases. To objectively classify place cells, we used criteria from Rotenberg et al. (1996). Thus, to be a place cell, the coherence was required to be $>0.26$, and the area of the largest field had to be $<70 \%$ of the apparatus area. Selection of place cells according to these criteria and by visual inspection was in exact agreement.

The stability of firing fields across session pairs was assessed with a rotational cross-correlation method. First, the pixel-by-pixel correlation was calculated for a pair of positional firing patterns. One pattern was then rotated in $3601^{\circ}$ steps, and at each step the correlation was recalculated. The magnitude of the highest of these correlations estimates the similarity of the two positional firing patterns. The angle of the highest correlation estimates how much one pattern is rotated with respect to the other. An ideal place cell would have identical firing-rate maps in each pair of the recording sessions, so that the maximal similarity score would be 1.0 and the required angular displacement would be $0^{\circ}$.

Theta frequency. We measured spectral power on EEG recordings using Clampfit 8.2 (Axon Instruments, Union City, CA) during times the rats were running in the cylinder for food pellets. Relative power for the frequency band from 2 to $20 \mathrm{~Hz}$ was calculated by averaging 12 epochs of 
A

Control

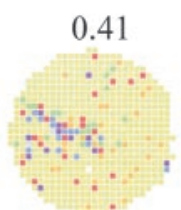

0.79

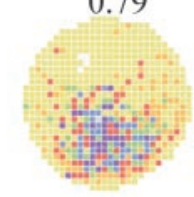

C

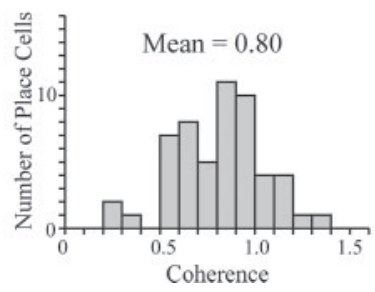

B 0.71

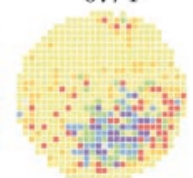
1.33

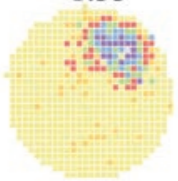

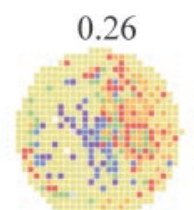

0.55

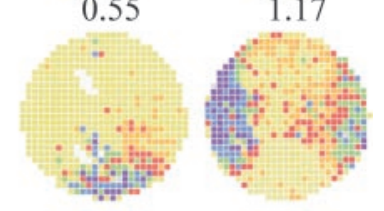

D

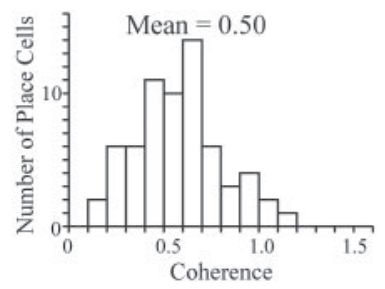

Figure 2. Organization of firing fields measured by coherence. Examples of firing rate maps from control $(A)$ and SE rats $(B)$. The number above each map is the coherence for the spatial firing pattern. The examples are chosen to reflect the coherence distributions for the two groups. C, D, Coherence histograms for 69 place cells from control rats ( $C$ ) and 66 place cells from SE rats $(D)$. Each coherence is the mean for all sessions for a given cell.

$10 \mathrm{sec}$ duration at a spectral resolution of $0.15 \mathrm{~Hz}$. Mean frequency of highest power in the theta range was calculated for the SE and control groups.

Water maze. Two hidden-platform water maze experiments were done on SE rats and matched controls by a blinded observer using techniques described previously (Holmes et al., 1998; Faverjon et al., 2002; Rutten et al., 2002). These were identical in design, except for the diameter of the water maze and the corresponding platform location. The first experiment, in a $1.15 \mathrm{~m}$ diameter tank, was done on the same rats from which single cell recordings were obtained. The second experiment, in a $2 \mathrm{M}$ diameter tank, was done on 10 control and 19 SE rats age matched to the recording groups, so that training and testing started at day P100. This group included the animals that had EEG recordings in addition to the place cell recordings.

In both experiments, a circular tank ( $50 \mathrm{~cm}$ high) was filled with water $\left(26 \pm 1{ }^{\circ} \mathrm{C}\right.$ ) to a depth of $25 \mathrm{~cm}$. Milk was added to the water to prevent the rat from seeing the platform. Room cues visible from the water surface were constant from day to day. Four points on the perimeter of the tank were designated north $(\mathrm{N})$, east (E), south (S), and west (W), dividing the tank into four quadrants (NW, NE, SE, and SW). For each rat, an $8 \times 8 \mathrm{~cm}$ Plexiglas escape platform was positioned in the center of one of the quadrants, $1 \mathrm{~cm}$ below the water surface. The radial distance from the center was 0.5 of the radius of the tank.

In our protocol, each rat was put in the tank for a $60 \mathrm{sec}$ swim with no platform on day 1 . On days $2-5$, the rat received six timed, hidden platform trials with the platform in the same quadrant across days. The starting quadrant for each trial was varied in pseudo-random manner. Time to platform was recorded by an observer blinded to the treatment group. In each trial, the rat was allowed $2 \mathrm{~min}$ to find the platform, where it could stay for $30 \mathrm{sec}$. If it failed to escape in $120 \mathrm{sec}$ it was removed from the water and put on the platform for $30 \mathrm{sec}$. At the end of a trial, the rat was lifted from the platform, dried with a towel, and put in the water for the next trial. On day 6, a probe test was done without the platform. The probe began with the rat in the quadrant opposite the trained platform location. The rat swam for $60 \mathrm{sec}$, and the time spent in each quadrant was recorded.

The testing procedure used during the $4 \mathrm{~d}$ of locating the hidden platform provides a measure of spatial reference memory, whereas the probe trial measures the strength of spatial memory (Jeltsch et al., 2001).

Place cell recording and water maze test after flurothyl-induced seizures. We used a chemical convulsant to produce acute epileptic seizures to assess: (1) the short-term consequences of epileptic seizures on place cell activity; and (2) relationships between possible epileptically induced, short-term changes in place cells and water maze performance. Seizures were induced in rats already trained in the water maze at a time when stable, identified place cells were being recorded.

The sequence of experience for five control rats was: (1) using the protocol described above plus an additional day, if necessary, rats were trained to asymptotic performance in the $1.15 \mathrm{~m}$ diameter water maze. The criterion was for the average latency to the platform to be $<10 \mathrm{sec}$ for three consecutive trials; (2) pellet chasing training for place cell recordings as described above; (3) electrode implantation; (4) place cell recording; (5) demonstration of place cell stability. By this, we mean that the angular displacement for recognizable firing fields was $<10^{\circ}$ for three or more consecutive days; 6) retraining to asymptotic performance in the water maze immediately after the recordings. This was done on the recording day; 7) flurothyl-induced seizure (see below); and (8) alternation between single hidden platform trials in the water maze and place cell recordings. Single trials followed by recording were done 30, 60, and 120 min and $24 \mathrm{hr}$ after the flurothyl seizure.

Brief seizures were induced with flurothyl (bis-2,2,2-triflurothyl ether; Aldrich Chemical Co., Milwaukee, WI) (Holmes et al., 1998; Huang et al., 1999; Villeneuve et al., 2000; Sogawa et al., 2001), a rapidly acting, potent CNS stimulant. After putting a rat in a small container, a piece of flurothyl-saturated filter paper was suspended from the container neck and the lid was put on. The flurothyl evaporated and was inhaled by the rat. Typically, flurothyl caused, in sequence, myoclonic seizures, vigorous running, and tonic and clonic activity. When tonic posturing developed, the rat was removed from the container to recover in room air.

Histology: Timm staining. At the end of the experiment, rats were killed with a lethal dose of sodium pentobarbital $(65 \mathrm{mg} / \mathrm{kg})$ and perfused transcardially with $200 \mathrm{ml}$ of normal saline, $200 \mathrm{ml}$ of sodium sulfide medium (2.925 gm of $\mathrm{Na}_{2} \mathrm{~S}$ and $2.975 \mathrm{gm}$ of $\mathrm{NaH}_{2} \mathrm{PO}_{4} \cdot \mathrm{H}_{2} \mathrm{O}$ in $500 \mathrm{ml}$ of $\mathrm{H}_{2} \mathrm{O}$ ), and $200 \mathrm{ml}$ of $4 \%$ paraformaldehyde (PFA). The brains were removed, postfixed in $4 \%$ PFA for $24 \mathrm{hr}$, and placed in $30 \%$ sucrose for 24 $\mathrm{hr}$ or longer until the brains sank. Coronal sections along the entire extent of the hippocampus were cut at $30 \mu \mathrm{M}$ on a freezing microtome and stored in PBS. Every fourth section was Timm stained for mossy fibers.

For Timm staining, sections were developed in the dark for 40-45 min in a solution of $50 \%$ gum arabic $(120 \mathrm{ml}), 10 \mathrm{ml}$ of citric acid $(51 \mathrm{gm} / 100$ $\left.\mathrm{ml} \mathrm{H}_{2} \mathrm{O}\right), 10 \mathrm{ml}$ of sodium citrate $\left(47 \mathrm{gm} / 100 \mathrm{ml} \mathrm{H} \mathrm{H}_{2} \mathrm{O}\right), 3.47 \mathrm{gm}$ of hydroquinone in $60 \mathrm{ml}$ of $\mathrm{H}_{2} \mathrm{O}$, and $212 \mathrm{mg}$ of $\mathrm{AgNO}_{3}$. Slides from control and SE rats were always stained at the same time. After washing, the slides were dehydrated in alcohol, cleared in xylene, and sealed with Permount.

Timm-stained sections were analyzed using a semiquantitative scale for terminal sprouting in CA3 and the supragranular region (Holmes et al., 1998, 1999). Timm staining in the pyramidal and infrapyramidal CA3 region and supragranular region was assessed on each section from the septal area in which the two blades of the dentate were equal and formed a V shape ( $2.8 \mathrm{~mm}$ posterior from the bregma) to a point $\sim 3.8 \mathrm{~mm}$ posterior to the bregma (Paxinos and Watson, 1998). Assessment of the Timm score in the supragranular region was done in the inferior blade of the dentate, avoiding the edge and crest of the gyrus. Both hippocampi of the specimens were analyzed, and the score given to the CA3 and supragranular regions reflected the mean for the two sides. Five sections per rat were evaluated.

Histology: thionin staining. To grade the degree of pathology present in portions of the hippocampus, thionin-stained slides were prepared from every fourth section. CA1, CA3, and the hilus were graded separately on the following scale: no cell loss $=0$; cell loss $<25 \%=1$; cell loss $25-$ $50 \%=2$; cell loss $50-75 \%=3$; no remaining cells $=4$ (Mikati et al., 1994; Schmid et al., 1999). Values for each region were taken as averages for the two hippocampi.

Statistical analysis. The values of all parameters in electrophysiological, 
behavioral, and histological experiments were expressed as mean $\pm \mathrm{SE}$. Measurements of individual place cell function were averaged for each rat in each group, and average scores were compared between groups. The $Z$ test was used to compare to the differences of the proportions of place cells, noisy cells, and silent cells in control and SE rats. Unpaired $t$ tests were used to compare field area, field rate, field center rate, coherence, Timm's staining scale, and cell loss scale. Differences in the maximal similarity and corresponding angular displacement within each group were compared with paired $t$ tests. In addition, differences in angular displacement and maximal similarity scores at the various time intervals were compared in the control and SE rats using the ANOVA with repeated measures. Unpaired $t$ tests were used to compare differences in the maximal similarity and the corresponding angular displacement between control and SE rats. A two-way repeated measures ANOVA was used to compare differences in water maze performance; $t$ tests were used to compare performance on each testing day. Correlations (Pearson $r$ ) were made between mean coherence values, angular displacement, and maximal similarity and mean time spent in the target quadrant during the probe test and cell loss and sprouting in the histological specimens. A $p \leq 0.05$ was considered statistically significant.

\section{Results}

\section{Status epilepticus}

Approximately 15-20 min after pilocarpine injection, rats began head bobbing, scratching, chewing, and exploratory-like behavior. Approximately 20-25 min after pilocarpine, intermittent head and bilateral forelimb myoclonus with rearing and falling were seen. These signs increased in severity over the next $60 \mathrm{~min}$. Intense clonic activity with episodes of rearing and falling occurred for the next 6-8 hr. A sequence obeying this general description occurred for all SE rats.

\section{Spontaneous seizures}

Spontaneous behavioral seizures occurred at least once in 18 of 28 (64.3\%) SE rats but were never seen in control rats. The seizures consisted of facial twitching, head nodding, and unilateral, alternating, or bilateral forelimb clonus; they lasted $<30 \mathrm{sec}$. Extrapolated mean seizure frequency based on the $6 \mathrm{hr}$ recording session was $0.75 \pm 0.17$ seizures $/ 24 \mathrm{hr}$. We did not proceed with recording if seizures were seen in the $6 \mathrm{hr}$ before the recording session. In addition, place cell recordings were stopped if the animal had a seizure during the study. Thus, the place cell activity described next was measured in the absence of behaviorally or electrically detectable seizure activity. Similar precautions were taken while later assessing water maze performance of these rats.

\section{Place cell discharge is less precise in SE rats}

According to the spike classification criteria outlined in Materials and Methods, we recorded $87 \mathrm{CA} 1$ pyramidal cells from 8 control rats and 74 pyramidal cells from 12 SE rats. A complex spike generated by a pyramidal cell in a control rat is shown in Figure $1 A$; a complex spike from a pyramidal cell in an SE rat is shown in Figure $1 B$. Pyramidal cells were further subdivided into place cells, noisy cells, and silent cells; examples of each are shown in Figure $1 C$ for control rats and Figure $1 D$ for SE rats. Of the 87 pyramidal cells recorded from control rats, $69(79.3 \%)$ were place cells, $11(12.6 \%)$ were noisy cells, and $7(8.0 \%)$ were silent cells. Of the 74 pyramidal cells from SE rats, $66(89.2 \%)$ were place cells, 4 (5.4\%) were noisy cells, and 4 (5.4\%) were silent cells. No reliable differences were found in the proportions of place cells $(Z=1.37 ; p=0.19)$, noisy cells $(Z=-0.55 ; p=0.58)$, and silent cells $(Z=-1.06 ; p=0.29)$ in control and SE rats. Thus, this simple analysis reveals no gross defect of pyramidal cell organization in SE rats.

CA1 pyramidal cells judged as place cells in SE rats appeared
Table 1. Comparisons of several characteristics of place cells in control and SE rats

\begin{tabular}{lccccc}
\hline & Mean \pm SEM & & & $t$ test & \\
\cline { 2 - 3 } \cline { 5 - 6 } Characteristics & Control & SE & & $t$ & $p$ \\
\hline Field area (pixels) & $132.20 \pm 22.90$ & $203.00 \pm 33.33$ & & 1.57 & 0.13 \\
Field center rate $(\mathrm{Hz})$ & $7.64 \pm 0.79$ & $7.37 \pm 0.92$ & & 0.20 & 0.84 \\
Field rate $(\mathrm{Hz})$ & $2.45 \pm 0.21$ & $2.66 \pm 0.30$ & & 0.51 & 0.61 \\
\hline
\end{tabular}

Control, $n=8 ; \mathrm{SE}, n=12 ; \mathrm{df}=18$

normal in several other ways. Specifically, we saw no differences between control place cells and place cells from the SE rats in field area, field center firing rate, or field firing rate (Table 1). Given these similarities, it is remarkable and exciting that place cells in the two groups differed strikingly according to "coherence," which measures the local smoothness of spatial firing patterns. Firing rate maps selected to reflect typical coherences for control place cells and place cells from the SE rats are shown in Figure 2, $A$ and $B$. Corresponding coherence histograms are shown in Figure 2, $C$ and $D$, where a clear shift to lower values is visible for place cells from the SE rats. Numerically, the mean coherence for control place cells of $0.80 \pm 0.05(n=8)$ was reliably higher than the mean of $0.50 \pm 0.06$ for the place cells $(n=12)$ from the SE rats $(t=3.80 ; \mathrm{df}=18 ; p=0.0013)$. Thus, firing field organization is weaker in adult rats subjected to SE during pubescence. Furthermore, this weaker organization is not secondary to other firing pattern defects such as decreased rates or major changes in the positional distribution of place cell discharge as measured by field area or information content.

\section{Place cells are less stable in SE rats}

We next asked whether the positional firing patterns of the place cells from the SE rats are stable over time. To this end, we ran four recording sessions for each control cell and cell from the SE rats within a $7 \mathrm{hr}$ period. Place cells in the control rats seemed stable (Fig. 3A); their fields remained in approximately the same position and retained their shapes across the four recording sessions. In marked contrast, the positional firing patterns of SE rats often changed considerably over time (Fig. $3 B$ ).

Stability was assessed numerically by computing rotational cross-correlation profiles for pairs of recording sessions. We evaluated six session pairs from the four recording sessions: two pairs (S1-S2 and S3-S4) with 2-3 min intersession intervals and four pairs (S1-S3, S1-S4, S2-S3, and S2-S4) with 4-6 hr intersession intervals. The two short interval and four long interval pairs were averaged for each cell (Fig. 4) and for each rat (Fig. 5). The mean angular displacement for control place cells was $6.60 \pm 1.70^{\circ}$ at the short interval and $9.40 \pm 2.59^{\circ}$ at the long interval. The mean angular displacement for place cells from SE rats was $35.25 \pm$ $6.55^{\circ}$ at the short interval and $43.39 \pm 8.10^{\circ}$ at the long interval. The differences in angular displacement between the control and $\mathrm{SE}$ rats were significant for both the short interval $(t=3.03$; $\mathrm{df}=$ $16 ; p=0.008)$ and long interval $(t=2.89 ; \mathrm{df}=16 ; p=0.011)$ sessions. The mean maximal similarity for control place cells was $0.61 \pm 0.03$ at the short interval and $0.59 \pm 0.04$ at the long interval. The mean maximal similarity for place cells from SE rats was $0.40 \pm 0.03$ at the short interval and $0.37 \pm 0.03$ at the long interval. The differences in maximal similarity between the control and SE rats were quite significant for both the short interval $(t=3.81 ; \mathrm{df}=16 ; p=0.0015)$ and long interval $(t=4.29 ; \mathrm{df}=$ $16 ; p<0.001)$ sessions.

We also used ANOVA with repeated measures to examine angular displacement and similarity scores between sessions S1 and S2, S1 and S3, and S1 and S4. For both angular displacement 
A

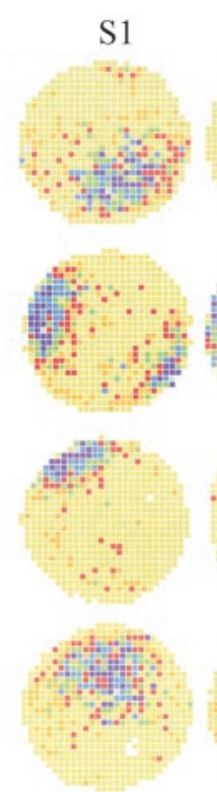

Control

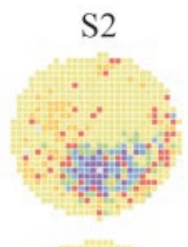

S3

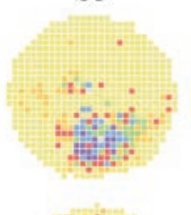

S4
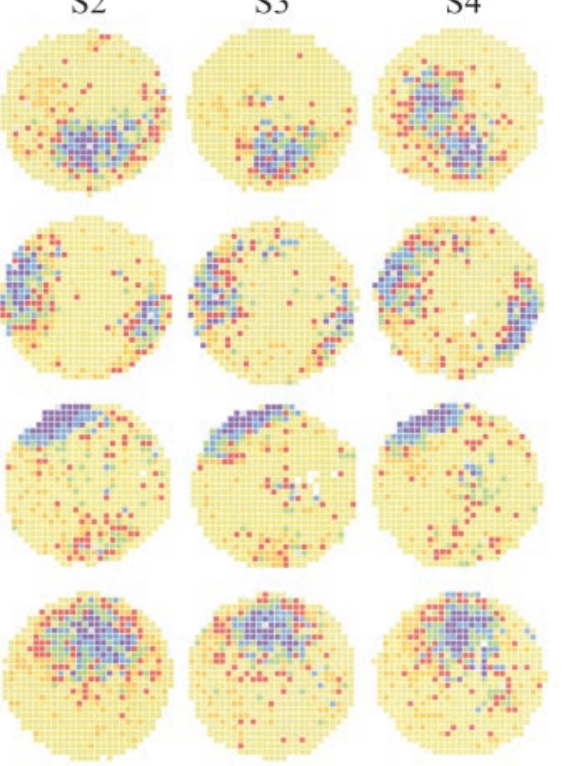

B

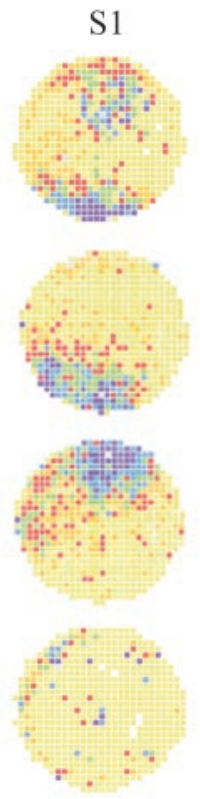

SE

S2
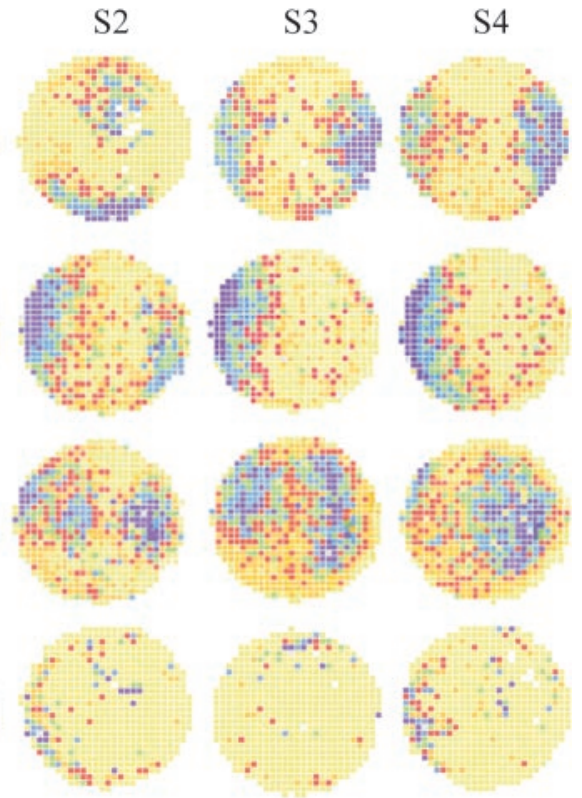

Figure 3. Examples of the stability of place cell firing patterns. $A$, Control rats. Each row shows rate maps from four successive recording sessions for a single place cell from a different rat. The intervals between sessions 1 and 2 and between sessions 3 and 4 were 3 min; the interval between sessions 2 and 3 was $4-6 \mathrm{hr}$. Each cell is quite constant across the four sessions. B, SE rats. Each row shows rate maps from four successive sessions. The fields vary considerably from session to session.

and maximal similarity scores, the differences between groups were highly significant (angular displacement: $F_{(1,22)}=27.39$; $p<0.001$; maximal similarity score: $\left.F_{(1,22)}=34.53 ; p<0.001\right)$. Differences between sessions were not significant (angular displacement: $F_{(1,22)}=0.029 ; p=0.972$; maximal similarity score: $\left.F_{(1,22)}=0.809 ; p=0.454\right)$

\section{Power spectrum}

Power spectrum analysis of the mean peak theta frequency calculated during running in the cylinder was similar in the controls $(7.23 \pm 0.17)$ and SE rats $(7.38 \pm 0.10)(t=0.74 ; \mathrm{df}=12 ; p=$ $0.48)$. Despite marked differences in place cell precision and stability between the controls and SE rats, the oscillatory properties of the hippocampus are basically intact in the SE rats.

\section{Impaired spatial performance in SE rats: small tank water maze}

After completion of the place cell recordings, we trained and tested these control and SE rats in a hidden platform version of the Morris swimming task in a tank $1.15 \mathrm{M}$ in diameter. Time to find the platform on the first trial was very similar for the two groups (control, $38.40 \pm 14.50 \mathrm{sec}$; SE, $51.60 \pm 15.70 \mathrm{sec}$ ), suggesting equal motor capacity and motivation $(t=0.61$; $\mathrm{df}=16$; $p=0.55)$. An ANOVA revealed that the SE rats were significantly slower than controls in learning to efficiently find the platform over the $4 \mathrm{~d}$ protocol. As seen in Figure $6 A, t$ tests for individual days showed that swim time by $\mathrm{SE}$ rats was reliably slower on days 1 and 2 but not on days 3 and 4, showing that they could eventually find the hidden platform in the small tank as well as the controls. A $60 \mathrm{sec}$ no-platform probe trial conducted on day 5 showed that both groups of rats spent excessive time in the goal quadrant (control, $19.70 \pm 1.31 \mathrm{sec}$; SE, $16.80 \pm 1.23 \mathrm{sec}$ ), but only a trend for the dwell time of the control rats to be more focused $(t=1.60 ; \mathrm{df}=16 ; p=0.13$ ) (Fig. $6 A)$. Thus, testing in a small water maze indicates that spatial memory performance in adults is not greatly impaired by SE during pubescence.

\section{Impaired spatial performance in SE rats: large tank water maze}

On inspection of swimming paths in the small water maze, it became apparent that neither control nor SE rats were, in general, taking straight-line paths to the hidden platform. Instead, most rats on most trials maintained a fixed distance from the wall and swam in an arc that allowed them to bump onto the platform. It was, therefore, possible that the use of a simple, non-geodesic solution was obscuring hippocampus-based deficiencies in navigational ability in SE rats. To test this possibility, we did a second swimming experiment in a larger ( $2 \mathrm{M}$ diameter) tank using control and SE rats age matched to the individuals used in place cell recordings. Except for the identities of the animals and the size of the tank, the two swimming experiments were identical.

In the large tank, SE rats took longer to reach the hidden platform than controls $\left(F_{(1,18)}=24.99 ; p<0.001\right)$. The $t$ tests for individual days showed that SE rats performed significantly poor on days 1-4 (Fig. 6B). The performance deficit of SE rats was not a result of slower swimming, which averaged $22.70 \pm 0.70 \mathrm{~cm} / \mathrm{sec}$ for control rats and $24.30 \pm 0.90 \mathrm{~cm} / \mathrm{sec}$ for SE rats $(t=0.19$; $\mathrm{df}=$ $18 ; p=0.19$ ). Likewise, the time to reach the platform on the first trial is indistinguishable in control and SE rats (control, $105.70 \pm$ $8.17 \mathrm{sec}$; SE, $108.40 \pm 10.30 \mathrm{sec}$ ), suggesting that the two groups were comparable in motivation and motor function $(t=0.21$; $\mathrm{df}=18 ; p=0.84)$. Note that by the fourth training day that the improvement shown by each group seemed to reach an asymptote, implying that the SE rats were permanently deficient in locating the hidden goal.

In a probe test of spatial memory, the platform was removed the day after the last training day. Rats were allowed $60 \mathrm{sec}$ to search for the absent platform. Control rats spent almost half the 

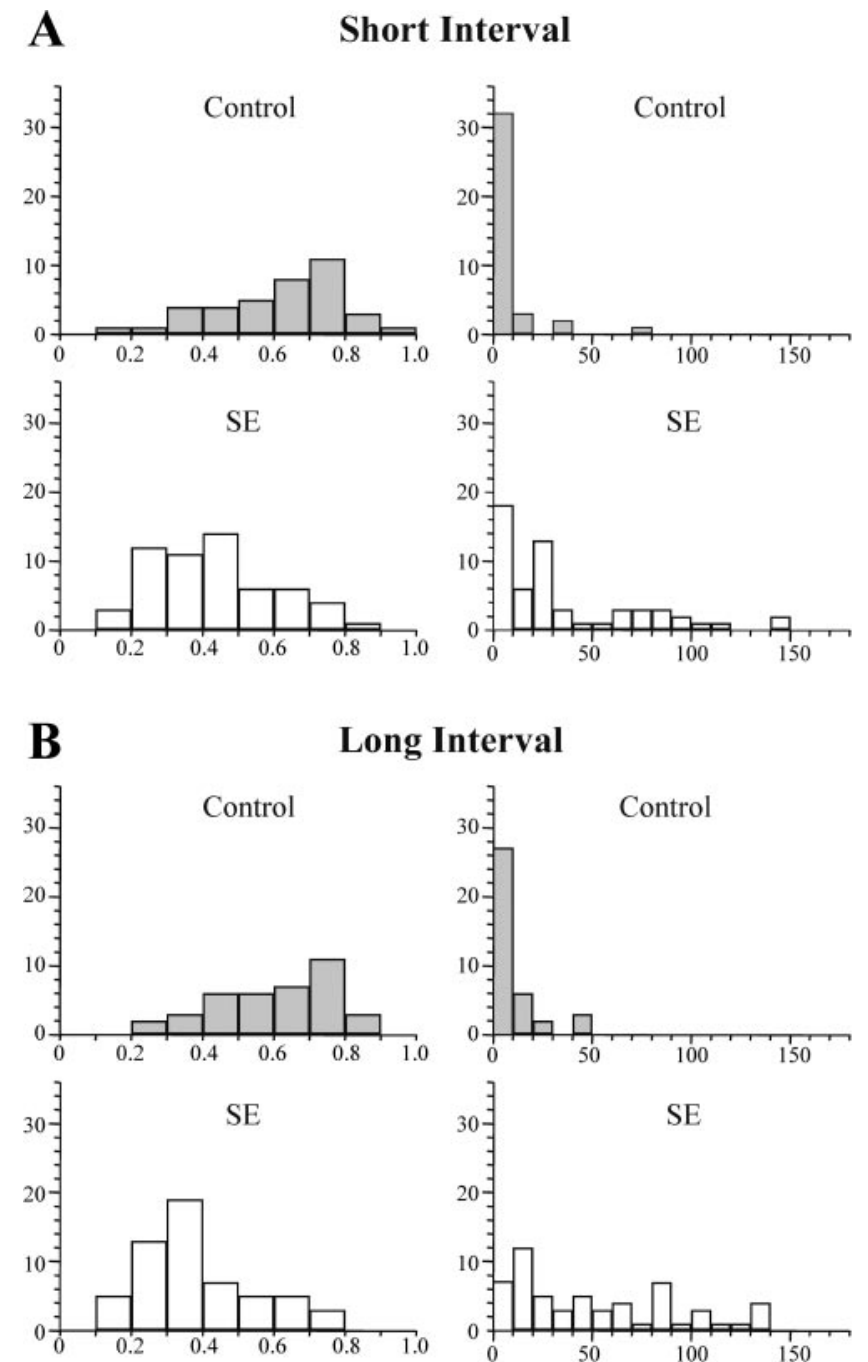

Maximal Similarity

Figure 4. The positional firing patterns of place cells from SE rats are less stable. Histograms of two measures of stability in individual place cells. The left column shows maximal similarity distributions for control and SE place cells; the right column shows corresponding angular displacement distributions. Histograms for these measures are shown for the short intersession interval on the top and for the long intersession interval on the bottom. Histograms for control place cells are labeled and shown on a gray background; histograms for SE place cells are labeled and shown on a white background. For both the short and long intersession intervals, the distribution is shifted to lower values for maximal similarity and to higher values for angular displacement in the SE place cells.

time $(28.90 \pm 2.63 \mathrm{sec} ; n=10)$ in the trained quadrant, whereas SE rats showed no preference for the trained quadrant, spending only about one-quarter $(15.16 \pm 1.10 \mathrm{sec} ; n=19)$ of their time there (Fig. $6 B$ ). The high $t$ statistic comparing goal quadrant time by the two groups $(t=5.59$; $\mathrm{df}=27$; $\mathrm{p} \ll 0.001)$ confirms the great navigational impairment of SE rats.

The nature of the SE-induced deficits revealed by water maze testing depends on the size of the swimming tank and the kind of solution used by the control rats. Thus, when control rats chose indirect routes in the small tank, the main impairment for SE rats was learning rate; after 4 training days, their performance caught up with that of the controls. In contrast, the increased uncertainty of the location of the platform in the larger tank apparently caused control rats to use a more advanced, perhaps map-based, strategy that allowed for near optimum routes. In this case, the SE
A Short Interval
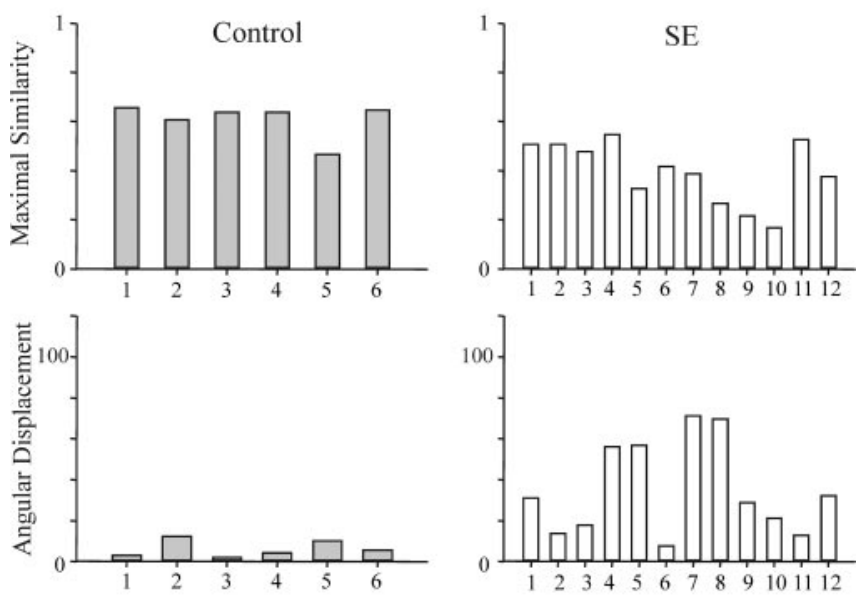

B

Long Interval
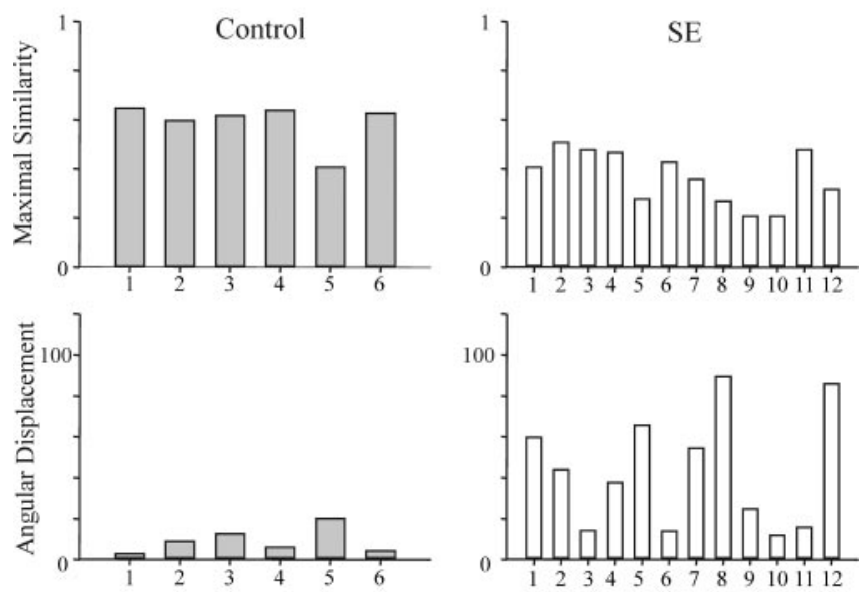

Figure 5. The positional firing patterns of place cells from SE rats are greatly variable. Histograms of two measures of stability in individual rats are shown. The left column shows maximal similarity and angular displacement distributions of place cells from the control rats; the right column shows those from the SE rats. Histograms for these measures are shown for the short intersession interval on the top and for the long intersession interval on the bottom. Histograms for control place cells are labeled and shown on as a gray background; histograms for SE place cells are labeled and shown as a white background. Both the short and long intersession intervals the distribution is shifted to lower values for maximal similarity and to higher values for angular displacement in the SE place cells. Rat number is listed below graphs.

rats presumably could not generate the computations necessary for optimum routes and, therefore, could not get to the platform as rapidly.

\section{Place cell function and water maze performance}

To determine whether there was a relationship between place cell function and water maze performance, we compared coherence, angular displacement, and maximal similarity scores with results of the probe test in the water maze in the large tank. There were significant correlations between coherence (Pearson $r=0.83 ; p=$ $0.002)$, angular displacement at the short interval $(r=0.787$; $p=0.005)$, angular displacement at the long interval $(r=0.70 ; p=$ $0.017)$, maximal similarity score at the short interval $(r=0.77$; $p=0.006)$, and maximal similarity score at the long interval $(r=$ $0.79 ; p=0.004)$. These findings demonstrate a close relationship 
between place cell precision and stability with water maze performance.

\section{Mossy fiber sprouting and cell loss after SE}

To complement single cell and behavioral measurements after SE, we also looked for structural changes in hippocampal formation. As shown in Figure 7, mossy fiber sprouting was present in both the supragranular region and CA3 subfield. The mean score for mossy fiber sprouting for $\mathrm{SE}$ rats in the CA3 subfield was higher than the mean for control rats $(\mathrm{SE}, 2.70 \pm 0.41$; control, $1.01 \pm 0.16 ; t=3.35 ; \mathrm{df}=16 ; p=$ $0.004)$. The mean score of mossy fiber sprouting in the supragranular region in the SE rats was also higher than the mean in control rats (SE, $3.50 \pm 0.60$; control, $0.44 \pm 0.12 ; t=4.96 ; \mathrm{df}=16 ; p \ll 0.001)$.

Modest pyramidal cell loss was seen in the CA3 subfield of the SE rats compared with the controls (SE, $1.01 \pm 1.23$; control, $0.43 \pm$ $0.14 ; t=3.14 ; \mathrm{df}=14 ; p=0.007)$. There was a trend toward cell loss in CA1 but not in the hilus (data not shown).

To determine whether there was a relationship between place cell function, water maze performance, and histological abnormalities, we compared histological scores and place cell measures with results of the probe test in the water maze in the large tank. There were significant correlations between the probe test and mossy fiber sprouting in CA3 $(r=0.48 ; p=0.045)$, CA1 $(r=$ $0.787 ; p=0.005)$, and cell loss in CA3 $(r=0.64 ; p=0.007)$. In addition, maximal similarity had a significant correlation with sprouting at both the short and long interval in CA3 (short: $r=$ $0.59, p=0.015$; long: $r=0.53, p=0.034$ ) and CA1 (short: $r=$ $0.66, p=0.006$; long: $r=0.53, p=0.034$ ). Angular displacement was significantly correlated with cell loss in CA3 at both the long and short intervals (short: $r=0.60, p=0.018$; long: $r=0.52, p=$ $0.05)$. Coherence was significantly correlated with cell loss in CA3 $(r=0.54 ; p=0.037)$.

\section{Acute seizures transiently abolish place cell activity and impair water maze performance}

In addition to chronic abnormalities in SE rats, we asked whether acute seizures would affect firing fields and, if so, whether such seizures would, in parallel, impair water maze performance. We studied five control rats that had yielded good place cells and who performed well in the water maze, as shown by escape latencies $<10 \mathrm{sec}$ on three consecutive trials.

In this protocol, the baseline firing patterns for six place cells and six theta cells were obtained in an initial recording session. Next, brief seizures were induced with flurothyl. When tonic posturing developed, the rat was returned to room air. Clonic activity continued for 1-2 $\mathrm{min}$, followed by a short period of impaired responsiveness. Within $10 \mathrm{~min}$ after the end of flurothyl exposure, rats began to walk around in the cage in an apparently normal manner. Nevertheless, they were severely impaired in a water maze test 20 min later; they swam at normal speeds using normal motor patterns but never reached the escape platform in the allotted $120 \mathrm{sec}$. In a post-seizure recording session immediately after the water maze trial, five of the six place cells from four rats were virtually silent. The six theta cells from four rats continued to be active, although their firing rates were reduced. In one rat, neither firing field location nor latency to platform in the

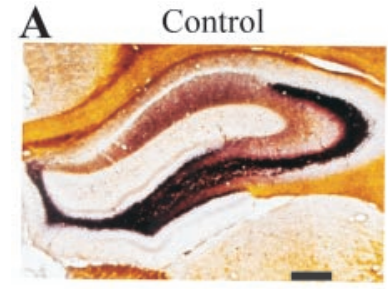

B Large Tank
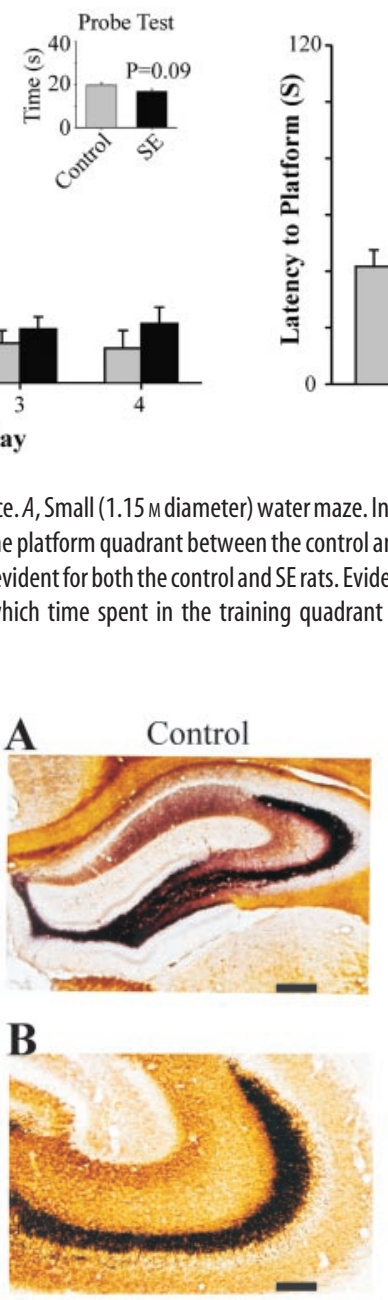

Testing Day

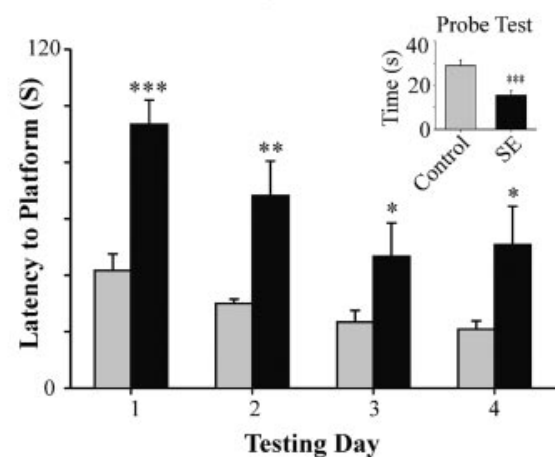

Testing Day
C
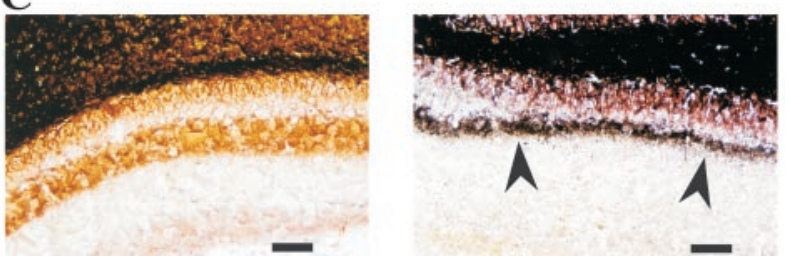

Figure 7. Timm staining in a control rat (left) and an SE rat (right). Displaced Timm granules are seen in strata oriens and pyramidale of $C A 3$ (arrows) and in supragranular dentate gyrus (arrowheads) in the SE rat but not in the control rat. Calibration: $A, 100 \mu \mathrm{m} ; B, 50 \mu \mathrm{m} ;$ C[SCAP], $25 \mu \mathrm{m}$.

water maze performance changed detectably after a flurothylinduced acute seizure.

With time after the seizure, place cell activity began to resume, and this occurred in parallel with improvements in water maze performance. Some recovery of place cells and swimming performance was seen $60 \mathrm{~min}$ after the seizure in five place cells from three rats. By $24 \mathrm{hr}$, in two rats in which the cells were held, the firing patterns of four place cells and water maze performance returned to near baseline. Figure 8 shows water maze performance and place cell activity from a representative rat before a seizure, $30 \mathrm{~min}$ after a seizure, and $24 \mathrm{hr}$ after a seizure. In the other three rats, water maze performance fully recovered after 24 hr, but the place cells were lost. Thus, to the extent we could follow post-seizure place cell discharge, single-cell activity and 


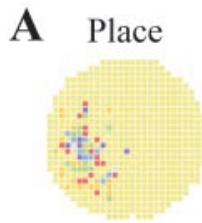

B
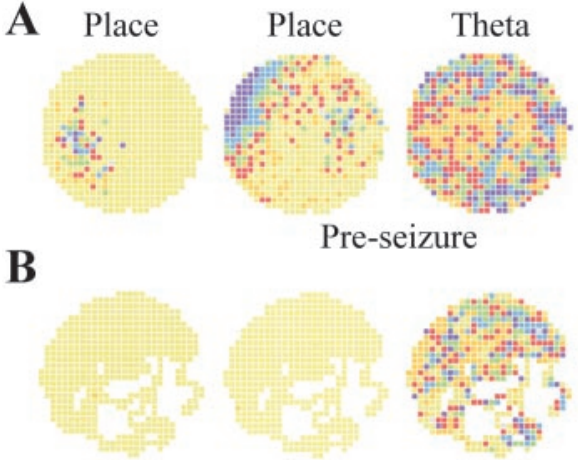

C

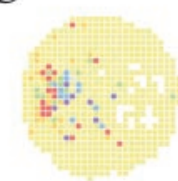

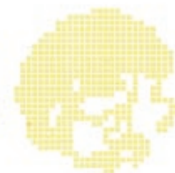

20 minutes after seizure

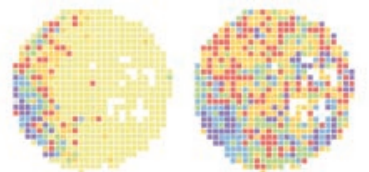

24 hours after seizure
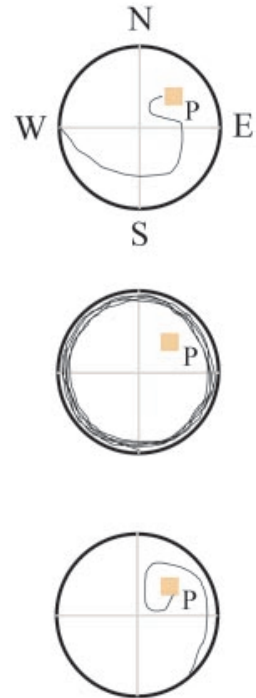

Figure 8. Rapid, parallel changes of place cell firing patterns and water maze performance after flurothyl-induced seizures in a control rat. The three cells were recorded simultaneously in all three sessions. $A$, The firing patterns of two place cells and one theta cell before the flurothyl seizures. Shortly after this recording session, water maze performance was accurate. $B$, In the interval between $20-36 \mathrm{~min}$ after a seizure, both place cells were silent. The theta cell fired, but at a lower rate. Twenty minutes after the seizure, the rat swam in circles at the tank edge and could not find the platform. C, Twenty-four hours after the seizure, both place cells discharged in a manner similar to pre-seizure patterns. By this time, water maze performance had returned to baseline.

behavioral performance were either abnormal or both recovered; on no occasion did they conflict with each other.

\section{Discussion}

In agreement with previous work (Yang et al., 2000; Wu et al., 2001; Faverjon et al., 2002; Rutten et al., 2002), we find that epileptic activity on two very different time scales interferes with spatial memory in rats. On a long time scale, SE induced in P20 rats causes spatial memory deficits that persist into adulthood. Thus, performance by mature SE rats was impaired on the hidden platform version of the Morris swimming task in both a small ( $1.15 \mathrm{~m}$ diameter) and a large ( $2 \mathrm{M}$ diameter) tank. The observed pattern of poor water maze performance by SE rats indicates a lasting, and presumably permanent, deficit in navigational memory, a form of memory that depends on intact hippocampal function in rodents. The fact that this defect of cognitive behavior is observed in rats with abnormal place cells at the network level and abnormal connectivity at the structural level (see below) suggests that the episode of SE during pubescence may underlie all of these problems and, moreover, that the problems are strongly related.

On a short time scale, brief acute seizures in otherwise normal adult rats cause severe, but transient, deficits in spatial memory. Shortly after the seizure, rats showed no knowledge of the hidden platform location despite excellent performance on previous trials and on trials $24 \mathrm{hr}$ after the seizure. Our main new contribution is the demonstration that these epilepsy-induced deficiencies of spatial memory are accompanied by abnormalities of place cell activity and that these place cell abnormalities correlate with the behavioral problems seen after both SE and acute seizures.

For SE rats, we saw two defects of place cell activity: (1) the coherence (local smoothness) of firing fields is lower; and (2) fields are less stable than those in control place cells. On the assumption that place cell activity is essential to normal navigational behavior, the decreased coherence helps account for the poorer water maze performance shown by SE rats. In addition, the apparent confinement of the within-session place cell defect to in-field organization implies that firing rate contours are important for navigation because the grosser division of the environment into fields and not-fields appear normal. It is crucial to note that both the place cell abnormalities and the to-beexplained behavioral deficits are seen in adult rats long after a single bout of SE and that both processes are persistent and, perhaps, permanent.

For rats subjected to an acute seizure, we saw a single, profound defect of place cell activity: that the cells were transiently silent after the seizure. Crucially, this silence had a time course similar to the post-seizure behavioral deficit, at least within the time resolution of our methods. Note that by comparing the chronic effects of SE and the acute effects of a seizure, another interesting parallel is seen: the partial disruption of spatial memory caused by SE was accompanied by defective place cells, whereas the complete failure of spatial information recall after the seizure was accompanied by a complete cessation of place cell activity.

The close links between the network and behavioral consequences of epileptic events lead in two quite different directions. First, they represent another instance in which there is a strong relationship between hippocampal place cells and deficits in learning, performance, or recall of complex spatial tasks. By now, it is clear that frank destruction of the hippocampus and its place cells (O'Keefe and Nadel, 1978; Olton et al., 1978; Morris et al., 1982; Sutherland et al., 1982), abnormal place cells in genetically modified mice (Rotenberg et al., 1996, 2000; Kang et al., 2001), or partial disruption of place cell activity caused by blockade of muscarinic cholinergic transmission (Brazhnik et al., 2003) lead to disruptions of spatial memory. In fact, experience-induced interference of control of place cells by sensory cues needed to solve spatial problems impairs performance in complex, but not simple, spatial tasks (Lenck-Santini et al., 2002).

The second sort of implication arising from our results concerns the origins of the memory deficits seen after SE in rats and possibly in people. Importantly, the events and processes that follow SE in rats imitate in many ways the events and processes seen in man (Dudek et al., 2002; Holmes et al., 2002). These parallels include: (1) the latent period that occurs after SE before epilepsy begins (French et al., 1993); (2) cellular damage in the hippocampus and neighboring regions (Liu et al., 1995); (3) spontaneous seizures (French et al., 1993); and (4) neuropsychological damage including, in rats, deficits of hippocampaldependent spatial memory, the closest parallel to episodic memory in humans (Spiers et al., 2001a,b).

However, it must be emphasized that the current studies are preliminary but provocative. It should be stressed that our study indicates there is a strong relationship between place cell abnormalities and impaired spatial ability. We have not demonstrated a causal relationship between the two. It should also be acknowledged that hippocampal place cell firing patterns can also be altered by abnormalities outside the hippocampus (Markus et al., 1994; Paz-Villagran et al., 2002; Muir and Bilkery, 2003). Nevertheless, this study, and others (Rotenberg et al., 1996, 2000), suggests that abnormalities in place cell firing patterns can be associated with adverse behavioral consequences.

At first glance, the ability of acute seizures to induce spatial performance deficits reminiscent of those seen after SE suggests that the abnormal electrical activity plays an essential role. It is 
here, however, that the ability to monitor place cell activity is shown to be of great advantage in elucidating relationships between gross abnormal electrical activity and memory problems. Assume momentarily that preceding seizure activity is responsible for poor performance in the water maze after SE as well as acute seizures. On this basis, we would expect that place cell discharge frequency in SE rats would be lower than in normal rats. But our place cell recordings indicate that discharge rate is no different in SE rats, despite the observation of other place cell defects that certainly can explain the performance deficits. In addition, we studied place cells in a subset of rats after SE that also underwent continuous EEG monitoring. The place cell abnormalities reported here were not associated with any seizures before or during the place cell recordings. Based on this evidence, we believe that permanent structural or functional rearrangements of hippocampal circuitry induced by SE are responsible for both the place cell and spatial memory deficits.

A fundamental question is why SE in prepubescent rats should lead to abnormal place cells when they become adults. SE rats results in a myriad of changes in the hippocampus, including cell death (Ben-Ari, 2001), increased neurogenesis (Sankar et al., 2001), changes in glutamate receptor distribution (Mathern et al., 1998; Mikuni et al., 1999) and glutamate subunit configuration (Friedman et al., 1997; Friedman, 1998), and synaptic reorganization with sprouting of mossy fibers (Sutula et al., 1988; Wuarin and Dudek, 2001). It is known that excessive mossy fiber sprouting leads to abnormal synaptic connections that have been associated with performance in visual-spatial memory tasks (Crusio et al., 1987, 1993; de Rogalski Landrot et al., 2001; Holmes et al., 1998). Although it is tempting to implicate the cell loss and synaptic reorganization seen here to the impaired place cell firing patterns and deficits in spatial memory, it is important to remember that correlation of two phenomena does not necessarily indicate causation. Teasing out the mechanisms responsible for the cognitive impairment after SE will likely be complex. However, place cell firing patterns provides a powerful tool in the elucidation of those factors responsible for SE-induced cognitive impairment

\section{References}

Aicardi J, Chevrie JJ (1970) Convulsive status epilepticus in infants and children. Epilepsia 11:187-197.

Aicardi J, Chevrie JJ (1983) Consequences of status epilepticus in infants and children. In: Advances in neurology, Vol 34, Status epilepticus: mechanisms of brain damage and treatment (Delgado-Escueta AV, Wasterlain CG, Treiman DM, Porter RJ, eds), pp 115-125. New York: Raven.

Ben-Ari Y (2001) Cell death and synaptic reorganizations produced by seizures. Epilepsia 42 [Suppl 3]:5-7.

Brazhnik ES, Muller RU, Fox SE (2003) Muscarinic blockade slows and degrades the location-specific firing of hippocampal pyramidal cells. J Neurosci 23:611-621.

Cilio MR, Sogawa Y, Cha BH, Liu X, Huang LT, Holmes GL (2003) Longterm effects of status epilepticus in the immature brain are age- and model-specific. Epilepsia 44:518-528.

Crusio WE, Schwegler H, Lipp H-P (1987) Radial-maze performance and structural variation of the hippocampus in mice: a correlation with mossy fiber distribution. Brain Res 425:182-185.

Crusio WE, Schwegler H, Brust I (1993) Covariations between hippocampal mossy fibers and working and reference memory in spatial and nonspatial radial maze tasks in mice. Eur J Neurosci 5:1413-1420.

de Rogalski Landrot I, Minokoshi M, Silveira DC, Cha BH, Holmes GL (2001) Recurrent neonatal seizures: relationship of pathology to the electroencephalogram and cognition. Dev Brain Res 129:27-38.

DeLorenzo RJ, Towne AR, Pellock JM, Ko D (1992) Status epilepticus in children, adults, and the elderly. Epilepsia 33 [Suppl 4]:S15-S25.

Dudek FE, Hellier JL, Williams PA, Dudek FE, Hellier JL, Williams PA (2002)
The course of cellular alterations associated with the development of spontaneous seizures after status epilepticus. Prog Brain Res 135:53-65.

Faverjon S, Silveira DC, Fu DD, Cha BH, Akman C, Hu Y, Holmes GL (2002) Beneficial effects of enriched environment following status epilepticus in immature rats. Neurology 59:1356-1364.

Fox SE, Ranck Jr JB (1975) Localization and anatomical identification of theta and complex spike cells in dorsal hippocampal formation of rats Exp Neurol 49:299-313.

Fox SE, Ranck Jr JB (1981) Electrophysiological characteristics of hippocamapal complex-spike cells and theta cells. Exp Brain Res 41:399-410.

French JA, Williamson PD, Thadani VM, Darcey TM, Mattson RH, Spencer SS, Spencer DD (1993) Characteristics of medial temporal lobe epilepsy: I. Results of history and physical examination. Ann Neurol 34:774-780.

Friedman LK (1998) Selective reduction of gluR2 protein in adult hippocampal CA3 neurons following status epilepticus but prior to cell loss. Hippocampus 8:511-525.

Friedman LK, Sperber EF, Moshé SL, Bennett MV, Zukin RS (1997) Developmental regulation of glutamate and $\mathrm{GABA}_{\mathrm{A}}$ receptor gene expression in rat hippocampus following kainate-induced status epilepticus. Dev Neurosci 19:529-542.

Hermann BP, Seidenberg M, Bell B (2002) The neurodevelopmental impact of childhood onset temporal lobe epilepsy on brain structure and function and the risk of progressive cognitive effects. Prog Brain Res 135:429-438

Holmes GL, Gaiarsa J-L, Chevassus-Au-Louis N, Ben-Ari Y (1998) Consequences of neonatal seizures in the rat: morphological and behavioral effects. Ann Neurol 44:845-857.

Holmes GL, Sarkisian M, Ben-Ari Y, Chevassus-Au-Louis N (1999) Mossy fiber sprouting following recurrent seizures during early development in rats. J Comp Neurol 404:537-553.

Holmes GL, Khazipov R, Ben Ari Y (2002) Seizure-induced damage in the developing human: relevance of experimental models. Prog Brain Res 135:321-334.

Huang L, Cilio MR, Silveira DC, McCabe BK, Sogawa Y, Stafstrom CE, Holmes GL (1999) Long-term effects of neonatal seizures: a behavioral, electrophysiological, and histolological study. Brain Res Dev Brain Res 118:99-107.

Jambaque I, Dellatolas G, Dulac O, Ponsot G, Signoret JL (1993) Verbal and visual memory impairment in children with epilepsy. Neuropsychologia 31:1321-1337.

Jeltsch H, Bertrand F, Lazarus C, Cassel JC (2001) Cognitive performances and locomotor activity following dentate granule cell damage in rats: role of lesion extent and type of memory tested. Neurobiol Learn Mem 76:81-105.

Kang H, Sun LD, Atkins CM, Soderling TR, Wilson MA, Tonegawa S (2001) An important role of neural activity-dependent CaMKIV signaling in the consolidation of long-term memory. Cell 106:771-783.

Krumholz A, Sung GY, Fisher RS, Barry E, Bergey GK, Grattan LM (1995) Complex partial status epilepticus accompanied by serious morbidity and mortality. Neurology 45:1499-1504.

Kubie JL (1984) A driveable bundle of microwires for collecting single-unit data from freely-moving rats. Physiol Behav 32:115-118.

Lenck-Santini P-P, Muller RU, Save E, Poucet B (2002) Relationships between place cell firing fields and navigational decisions by rats. J Neurosci 22:9035-9047.

Liu Z, Mikati M, Holmes GL (1995) Mesial temporal sclerosis: pathogenesis and significance. Pediatr Neurol 12:5-16.

Markus EJ, Barnes CA, McNaughton BL, Gladden VL, Skaggs WE (1994) Spatial information content and reliability of hippocampal CA1 neurons: effects of visual input. Hippocampus 4:410-421.

Mathern GW, Pretorius JK, Mendoza D, Lozada A, Kornblum HI (1998) Hippocampal AMPA and NMDA mRNA levels correlate with aberrant fascia dentata mossy fiber sprouting in the pilocarpine model of spontaneous limbic epilepsy. J Neurosci Res 54:734-753.

Mikati MA, Holmes GL, Chronopoulos A, Hyde P, Thurber S, Gatt A, Liu Z, Werner S, Stafstrom CE (1994) Phenobarbital therapy modifies seizure related brain injury in the developing brain. Ann Neurol 36:425-433.

Mikuni N, Babb TL, Christi W (1999) Increased NR1-NR2A/B coassembly as a mechanism for rat chronic hippocampal epilepsy. Neruosci Lett 267:165-168.

Morris RG, Garrud P, Rawlins JN, O'Keefe J (1982) Place navigation impaired in rats with hippocampal lesions. Nature 297:681-683. 
Muir GM, Bilkey DK (2003) Theta- and movement velocity-related firing of hippocampal neurons is disrupted by lesions centered on the perirhinal cortex. Hippocampus 13:93-108.

Muller RU, Kubie JL (1987) The effects of changes in the environment on the spatial firing patterns of hippocampal complex-spike cells. J Neurosci 7:1951-1968.

Muller RU, Kubie JL, Ranck Jr JB (1987) Spatial firing patterns of hippocampal complex-spike cells in a fixed environment. J Neurosci 7:1935-1950.

O'Keefe J, Nadel L (1978) The hippocampus as a cognitive map. Oxford: Clarendon.

Olton DS, Walker JA, Gage FH (1978) Hippocampal connections and spatial discrimination. Brain Res 139:295-308.

Paxinos G, Watson C (1998) The rat brain in stereotaxic coordinates, Ed 4. San Diego: Academic.

Paz-Villagran V, Lenck-Santini PP, Save E, Poucet B (2002) Properties of place cell firing after damage to the visual cortex. Eur J Neurosci 16:771-776.

Ranck Jr JB (1973) Studies on single neurons in dorsal hippocampal formation and septum in unrestrained rats. Exp Neurol 41:461-531.

Rotenberg A, Mayford M, Hawkins RD, Kandel ER, Muller RU (1996) Mice expressing activated CaMKII lack low frequency LTP and do not form stable place cells in the CA1 region of the hippocampus. Cell 87:1351-1361.

Rotenberg A, Abel T, Hawkins RD, Kandel ER, Muller RU (2000) Parallel instabilities of long-term potentiation, place cells, and learning caused by decreased protein kinase A activity. J Neurosci 20:8096-8102.

Rutten A, van Albada M, Silveira DC, Cha BH, Liu X, Hu YN, Cilio MR, Holmes GL (2002) Memory impairment following status epilepticus in immature rats: time- course and environmental effects. Eur J Neurosci 501-513.

Sahin M, Menache CC, Holmes GL, Riviello JJ (2001) Outcome of severe refractory status epilepticus in children. Epilepsia 42:1461-1467.

Sankar R, Shin D, Liu H, Katsumori H, Wasterlain CG (2001) Granule cell neurogenesis after status epilepticus in the immature rat brain. Epilepsia 41 [Suppl 6]:S53-S56.

Schmid R, Tandon P, Stafstrom CE, Holmes GL (1999) Effects of neonatal seizures on subsequent seizure-induced brain injury. Neurology 53:1754-1761.

Shinnar S, Pellock JM, Moshe SL, Maytal J, O’Dell C, Driscoll SM, Alemany M, Newstein D, DeLorenzo RJ (1997) In whom does status epilepticus occur: age-related differences in children. Epilepsia 38:907-914.

Sogawa Y, Monokoshi M, Silveira DC, Cha BH, Cilio MR, McCabe BK, Liu X, $\mathrm{Hu}$ Y, Holmes GL (2001) Timing of cognitive deficits following neona- tal seizures: relationship to histological changes in the hippocampus Brain Res Dev Brain Res 131:73-83.

Spiers HJ, Burgess N, Hartley T, Vargha-Khadem F, O’Keefe J (2001a) Bilateral hippocampal pathology impairs topographical and episodic memory but not visual pattern matching. Hippocampus 11:715-725.

Spiers HJ, Burgess N, Maguire EA, Baxendale SA, Hartley T, Thompson PJ, O'Keefe J (2001b) Unilateral temporal lobectomy patients show lateralized topographical and episodic memory deficits in a virtual town. Brain 124:2476-2489.

Squire LR (1992) Memory and the hippocampus: a synthesis from findings with rats, monkeys, and humans. Psychol Rev 99:195-231.

Stefan H, Pauli E (2002) Progressive cognitive decline in epilepsy: an indication of ongoing plasticity. Prog Brain Res 135:409-417.

Sutherland RJ, Whishaw IQ, Kolb BA (1982) A behavioral analysis of spatial localization following electrolytic, kainate- or colchicine-induced damage to hippocampal formation in the rat. Behav Brain Res 7:133-153.

Sutula T, He X-X, Cavazos J, Scott G (1988) Synaptic reorganization in the hippocampus induced by abnormal functional activity. Science 239:1147-1150.

Thompson LT, Best PJ (1989) Place cells and silent cells in the hippocampus of freely behaving rats. J Neurosci 9:2382-2390.

Thompson LT, Best PJ (1990) Long-term stability of the place-field activity of single units recorded from the dorsal hippocampus of freely behaving rats. Brain Res 509:299-308.

van Esch A, Ramlal IR, van Steensel-Moll HA, Steyerberg EW, DerksenLubsen G (1996) Outcome after febrile status epilepticus. Dev Med Child Neurol 38:19-24.

Villeneuve N, Ben-Ari Y, Holmes GL, Gaiarsa JL (2000) Neonatal seizures induced persistent changes in intrinsic properties of CA1 rat hippocampal cells. Ann Neurol 47:729-738.

Working Group on Status Epilepticus (1993) Treatment of convulsive status epilepticus. Recommendations of the Epilepsy Foundation of America's Working Group on Status Epilepticus. JAMA 270:854-859.

Wu CL, Huang LT, Liou CW, Wang TJ, Tung YR, Hsu HY, Lai MC (2001) Lithium-pilocarpine-induced status epilepticus in immature rats result in long-term deficits in spatial learning and hippocampal cell loss. Neurosci Lett 312:113-117.

Wuarin JP, Dudek FE (2001) Excitatory synaptic input to granule cells increases with time after kainate treatment. J Neurophysiol 85:1067-1077.

Yang Y, Liu Z, Cermak JM, Tandon P, Sarkisian MR, Stafstrom CE, Neill JC, Blusztajn JK, Holmes GL (2000) Protective effects of prenatal choline supplementation on seizure- induced memory impairment. J Neurosci 20:RC109. 